\title{
Hypothalamic alterations in fetuses of high fat diet-fed obese female rats
}

\author{
Anshu Gupta ${ }^{1,3}$, Malathi Srinivasan ${ }^{2}$, Supaporn Thamadilok ${ }^{2}$ and Mulchand S Patel ${ }^{2}$ \\ Departments of ${ }^{1}$ Biochemistry and Pediatrics, ${ }^{2}$ School of Medicine and Biomedical Sciences, University at Buffalo, State University of New York, 140 Farber \\ Hall, 3435 Main Street, Buffalo, New York 14214, USA \\ ${ }^{3}$ Women and Children's Hospital of Buffalo, Buffalo, New York 1422, USA \\ (Correspondence should be addressed to M S Patel; Email: mspatel@buffalo.edu)
}

\begin{abstract}
The offspring of high fat (HF) diet-fed rats display increased body weight during adulthood. However, it is not known whether the changes in appetite regulation in these animals occur in utero or postnatally. We investigated the effects of maternal obesity induced by a HF diet prior to and during pregnancy on leptin and insulin signaling and the expression of orexigenic and anorexigenic peptides in term fetal hypothalami. The consumption of a HF diet prior to and during pregnancy resulted in obesity in HF female rats; additionally, HF female rats exhibited hyperinsulinemia and hyperleptinemia which were exaggerated in late gestation compared with control female rats that were fed a standard rodent laboratory chow (LC). Term fetuses of HF female rats (FHF) also had significantly higher serum leptin and insulin levels compared with control fetuses (FLC) while there was no difference in average fetal weight between the two groups.
\end{abstract}

FHF hypothalami showed elevated levels of mRNA and proteins for leptin long receptor and insulin receptor $\beta$ subunit. However, the protein levels of signal transducers and activators of transcription-3 and insulin receptor substrate-2, the downstream signaling components of leptin and insulin signaling respectively were decreased. Also, FHF hypothalami had increased mRNA levels of neuropeptide $\mathrm{Y}$ and agoutirelated polypeptide indicating that orexigenic neuropeptides in HF progeny are already upregulated by term fetal stage. Additionally, the mRNA levels of pro-opiatemelanocortin and melanocortin receptor-4 were also increased in the HF fetal hypothalami. These findings indicate potential programming effects of an altered intrauterine environment induced by HF diet consumption on appetite-regulating neuropeptides and leptin and insulin signaling in the late fetal period.

Journal of Endocrinology (2009) 200, 293-300

\section{Introduction}

Recent studies published by the NHANES III survey point to an alarming increase in the prevalence of obesity, metabolic syndrome and type 2 diabetes in adults as well as in children (Flegal et al. 2002). In 1999-2000, within the US, $>15 \%$ of 6-19 year-old children, $10 \%$ of children between the ages of 2 and 5 years-old and more than $12 \%$ of 6-23 month-old infants were classified as obese ( $>95 \%$ body mass index (BMI); Flegal et al. 2002). This demographic shift in phenotype of obesity towards a younger age is not explained by genetic changes over the last 100 years. There is increasing evidence to indicate that genes interact with the intrauterine, perinatal and early postnatal environments of an organism leading to adaptations for immediate survival. However, over the long-term, these adaptations can predispose individuals to the development of the obese phenotype (Plagemann 2005). In the context of the phenomenon of developmental programming, obesity during pregnancy is implicated in playing a pathogenic role in the development of the obese phenotype in offspring. Children who are born to obese mothers are twice as likely to be obese by 2 years of age (Whitaker 2004). Abnormal maternal pregravid weight along with diabetes is an additional risk factor for adolescent obesity (Yogev \& Langer 2008). Adolescents born to obese mothers are also twice as likely to have metabolic syndrome if the mother is both diabetic and obese (Boney et al. 2005). A strong correlation exists between maternal BMI and the BMI of offspring in adulthood. Also, studies show an increased risk of large gestational age for babies if the mother has abnormal weight gain between successive pregnancies (Parsons et al. 2001, Villamor \& Cnattingius 2006). Fetal development in a diabeticintrauterine environment resulted in a diabetogenic tendency in the offspring (Van Assche et al. 2001). Among Pima Indians high birth weight resulting from abundant supply of glucose due to maternal diabetes during pregnancy predisposed the offspring to the development of diabetes later in life (Pettitt 1996). These epidemiological studies strongly indicate that the origins of obesity and metabolic syndrome lie in utero.

Animal studies in various models including gestational under-nutrition, infants of diabetic mothers, neonatal overnutrition, and glucocorticoid exposure provide valuable supportive evidence confirming the role of intrauterine 
environment in developmental metabolic programming of offspring. Studies in these diverse animal models of altered environment have shown a programming effect on growth, adipose tissue and the appetite regulating pathways in the brain in adult offspring resulting in an increased risk of type 2 diabetes, hypertension and cardiovascular dysfunction (Whitaker 2004, Plagemann 2005). Maternal overnutrition during pregnancy has been similarly demonstrated to lead to increased appetite, adiposity, impaired glucose tolerance and cardiovascular dysfunction in the offspring (Khan et al. 2005, Muhlhausler et al. 2006, Taylor \& Poston 2007).

The hypothalamus plays a central role in energy homeostasis by regulating both appetite and energy expenditure. The arcuate nucleus in the hypothalamus is the prime area involved in the control of food intake (Schwartz et al. 2000, Valassi et al. 2008). It contains two interconnected groups of 'first order' neurons which release the orexigenic neuropeptides (neuropeptide $\mathrm{Y}$ (NPY) and agouti-related peptide (AgRP)) and the anorexigenic substance pro-opiatemelanocortin (POMC; Schwartz et al. 2000, Valassi et al. 2008). The axons from these neurons project to second order neurons in the paraventricular nucleus and the lateral hypothalamic area where appropriate anabolic or catabolic pathways are activated in response to the peripheral signals received (Schwartz et al. 2000, Valassi et al. 2008).

The central nervous system maturation including that of the hypothalamus begins in utero and continues into early postnatal life. Therefore, changes in nutrient availability in the intrauterine and neonatal periods can cause permanent changes in expression of key appetite-regulating neuropeptides and their receptors. Neonatal overnutrition studies in suckling rats have demonstrated changes in expression of NPY and AgRP in the hypothalamus in association with hyperphagia and increased adiposity (Plagemann 2005). The mRNA levels of long form of leptin receptor $(\mathrm{OB}-\mathrm{Rb})$, NPY and AgRP were inversely related to total fat mass in lambs of over-nourished ewes pointing to a state of leptin resistance in the adult offspring (Muhlhausler et al. 2006). Adult offspring of prenatally overfed rats had an exaggerated feeding response to central NPY injection compared with control animals (Kozak et al. 2005). Studies from our laboratory have shown that artificial rearing of newborn rat pups on a high carbohydrate milk formula resulted in hypothalamic adaptations predisposing them to hyperphagia in the post-weaning period (Srinivasan et al. 2008).

Most studies on programming effects have been done in the neonatal period. However, considering that the hypothalamus starts developing in utero, it becomes imperative to segregate the effects of prenatal overnutrition on the offspring from effects of lactation and postnatal overnutrition. This is important for two reasons. First, unlike models that induce fetal hyperglycemia, maternal overfeeding models are more closely related to the current obesity epidemic. Secondly, if these effects are established during the fetal period, it will provide important supportive information to epidemiological studies for designing intervention strategies during the prenatal period to prevent permanent establishment of adverse programming effects in the offspring.
The present study evaluated the maternal and fetal environments during pregnancy complicated by obesity in rats fed a high-fat (HF) diet. We investigated the signaling pathways of insulin and leptin in the fetal hypothalamus to investigate putative alterations in downstream signaling as well as expression levels of neuropeptides involved in energy homeostasis. Knowledge of these changes will further our understanding of the role of leptin and insulin in the brain in the developing fetus.

\section{Materials and Methods}

\section{Animal experimentation}

All animal protocols were approved by the Institutional Animal Care and Use Committee. Newly weaned (postnatal day 23) Sprague-Dawley female rats were procured from ZivicMiller Laboratories (Zelienople, PA, USA) and housed under controlled conditions of light, temperature, and humidity. They were randomly assigned either to a standard rodent laboratory chow diet (LC; Harlan Teklad, Madison, WI, USA) or a high-fat diet (Product \# F3282; Bio-Serv; Frenchtown, NJ, USA) with access to water and their specific diets ad libitum. Two rats receiving the same diet were housed per cage from the time of weaning until initiation of breeding. The caloric composition of the HF diet was 24.4\% carbohydrate, $59 \cdot 5 \%$ fat and $16 \cdot 2 \%$ protein compared with $70 \%$ carbohydrate, $10 \cdot 9 \%$ fat and $19 \cdot 2 \%$ protein in the LC diet (Srinivasan et al. 2006). The energy densities of the diets were $5.3 \mathrm{kcal} / \mathrm{g}$ for HF and $3.2 \mathrm{kcal} / \mathrm{g}$ for LC.

The female rats were weighed weekly from postnatal day 25. Blood $(0.2 \mathrm{ml})$ was obtained from the tail site every 2 weeks for plasma analyses outlined below. At 100 days of age, the females were housed individually and mated with normal adult males fed a standard LC diet. Expulsion of vaginal plug was considered day one of gestation. The female rats were housed individually during pregnancy. The respective diets were continued during pregnancy for the females. Pregnant females were killed on day 21 of gestation and blood samples were obtained. For optimal blood sample amounts, term fetuses from each female were considered as a single unit and specimens were pooled from each litter. Plasma from female rats and sera from term fetuses were analyzed for insulin and leptin levels using rat RIA kits (Linco Research, St Louis, MO, USA).

\section{Isolation of hypothalami}

The skull was opened and the hypothalamus was dissected from the ventral side of the brain using the anatomical margins of the optic chiasm anteriorly and the mammillary bodies posteriorly. All the samples were snap frozen in liquid nitrogen and stored at $-80^{\circ} \mathrm{C}$ until subsequent analyses by PCR and western blot. 


\section{Quantitative RT-PCR}

Total RNA was extracted from the hypothalami of rat fetuses using the TRIZOL reagent phenol-chloroform procedure. (Gibco). One microgram of RNA was subsequently reverse transcribed into cDNA by using the iScript cDNA synthesis kit (Bio-Rad) according to the manufacturer's instructions and analyzed further using SYBR green quantitative PCR technique. Primer sequences were designed to span at least one exon-exon junction of the target mRNA to prevent amplification of contaminating genomic DNA using Primer 3 software and NLM sequence database. Primer sequences are described in Table 1. The mRNA levels detected by SYBR Green (Bio-Rad) analysis were normalized using 18S mRNA levels as endogenous reference standard. (Quantum RNA Classic II 18S Internal Standard, 324 bp; Ambion, Austin, TX, USA). Relative mRNA levels were calculated according to the comparative $\Delta \Delta C_{\mathrm{t}}$ method.

\section{Western blot analysis}

Total protein was extracted from pooled hypothalami of term rat fetuses. Briefly, 2 hypothalami were resuspended in $300 \mu \mathrm{l}$ solubilization buffer (50 mM HEPES, $137 \mathrm{mM} \mathrm{NaCl}, 1 \mathrm{mM}$ $\mathrm{MgCl}_{2}, 1 \mathrm{mM} \mathrm{CaCl}, 2 \mathrm{mM} \mathrm{NaVO}, 10 \mathrm{mM} \mathrm{NaP} \mathrm{O}_{7}$, $10 \mathrm{mM}$ NaF, 2 mM EDTA, 1\% Igepal, 10\% glycerol, $2 \mu \mathrm{g} / \mathrm{ml}$ aprotinin, antipain, leupeptin, and pepstatin, $1.5 \mu \mathrm{g} / \mathrm{ml}$ benzamidine, $34 \mu \mathrm{g} / \mathrm{ml}$ phenylmethylsulphonyl fluoride), homogenized by sonication and centrifuged. Equal amounts of protein $(20-50 \mu \mathrm{g})$ for both groups were separated by SDS-PAGE for determination of levels of the different proteins examined. Protein was transferred to a nitrocellulose membrane and incubated with primary and secondary antibodies as described earlier (Srinivasan et al. 2006). Protein bands were visualized using chemiluminescence (PerkinElmer, Wellesley, MA, USA), and densitometric analysis was performed using the Quantity One program. Antibodies were obtained from sources as indicated: OB-Rb (Linco Research), $\beta$-subunit of the insulin receptor (IR- $\beta$ ) and insulin receptor substrate-2 (IRS-2; Upstate Cell
Signaling, Chicago, IL, USA), signal transducers and activators of transcription-3 (STAT-3; Cell Signaling Solutions, Lake Placid, NY, USA) and suppressors of cytokine signaling-3 (SOCS-3; Affinity BioReagents, Golden, CO, USA).

\section{Statistical analysis}

All data are expressed as means \pm s.E.M. ( $n$ as indicated). Litter from one female was considered as a single observation. Oneway ANOVA followed by post hoc analysis using the StudentNewman-Keuls test was used to determine significance of the difference of the means of data for multiple time points. For analysis of data for a single time point Student unpaired $t$-test was performed. $P$ value $\leq 0 \cdot 05$ was considered as significant.

\section{Results}

\section{Body weight gain and food intake}

Our earlier studies showed that female rats fed a HF diet exhibited significant increases in weight gain by postnatal day 65 which was amplified over time (Srinivasan et al. 2006). The present study also showed that female rats weaned onto a high-fat diet were significantly heavier than age-matched LC female rats in the post-weaning period (Fig. 1A). During pregnancy $\mathrm{HF}$ female rats were markedly heavier than age-matched LC pregnant rats at the end of the first, second and third weeks of gestation (Fig. 1B). The HF diet is more calorie dense compared with the LC diet $(5 \cdot 3 \mathrm{kcal} / \mathrm{g}$ for HF diet and $3.2 \mathrm{kcal} / \mathrm{g}$ for LC diet). HF female rats consumed a significantly increased number of calories compared with age-matched LC female rats in the pre-pregnancy period (Fig. 1C) although in terms of weight of diet consumed there were no marked differences between the two groups of rats per each data point (data not shown). During gestation HF female rats continued to demonstrate hyperphagia as indicated by the increased caloric consumption during the third week of pregnancy (Fig. 1D).

Table 1 Primer sequences for quantitative RT-PCR

\begin{tabular}{|c|c|c|}
\hline OB-Rb & $370 \mathrm{bp}$ & $\begin{array}{l}\text { Sense: } 5^{\prime} \text {-CCTGAAACATTTGAGCATCTTT-3' } \\
\text { Antisense: } 5^{\prime} \text {-CGATGCACTGGCTGACAGAA-3' }\end{array}$ \\
\hline AgRP & 114 bp & $\begin{array}{l}\text { Sense: } 5^{\prime} \text {-AGCAGACCGAGCAGAAGATG-3' } \\
\text { Antisense: } 5^{\prime} \text {-GACTCGTGCAGCCTTACACA-3' }\end{array}$ \\
\hline NPY & $236 \mathrm{bp}$ & $\begin{array}{l}\text { Sense: 5'-AGAGATCCAGCCCTGAGACA-3' } \\
\text { Antisense: 5'-AACGACAACAAGGGAAATGG-3' }\end{array}$ \\
\hline POMC & $173 \mathrm{bp}$ & $\begin{array}{l}\text { Sense: } 5^{\prime} \text {-CGACGGAGGAGAAAAGAGGT-3' } \\
\text { Antisense: } 5^{\prime} \text {-CTATGGAGGTCTGAAGCAGGAG-3' }\end{array}$ \\
\hline IR- $\beta$ & $331 \mathrm{bp}$ & $\begin{array}{l}\text { Sense: } 5^{\prime} \text {-ATCTGGATCCCCCTGATAACTGTC-3' } \\
\text { Antisense: } 5^{\prime} \text {-ATGTGGGTGTAGGGGATGTGTTCA-3' }\end{array}$ \\
\hline STAT-3 & $104 \mathrm{bp}$ & $\begin{array}{l}\text { Sense: } 5^{\prime} \text {-TGATGCGCTCTTATGTGAGG-3' } \\
\text { Antisense: } 5^{\prime} \text {-GGCGGACAGAACATAGGTGT-3' }\end{array}$ \\
\hline SOCS-3 & 133 bp & $\begin{array}{l}\text { Sense: } 5^{\prime} \text {-CCTTTGAGGTTCAGGAGCAG-3' } \\
\text { Antisense: } 5^{\prime} \text {-GTAGCCACGTTGGAGGAGAG-3' }\end{array}$ \\
\hline
\end{tabular}



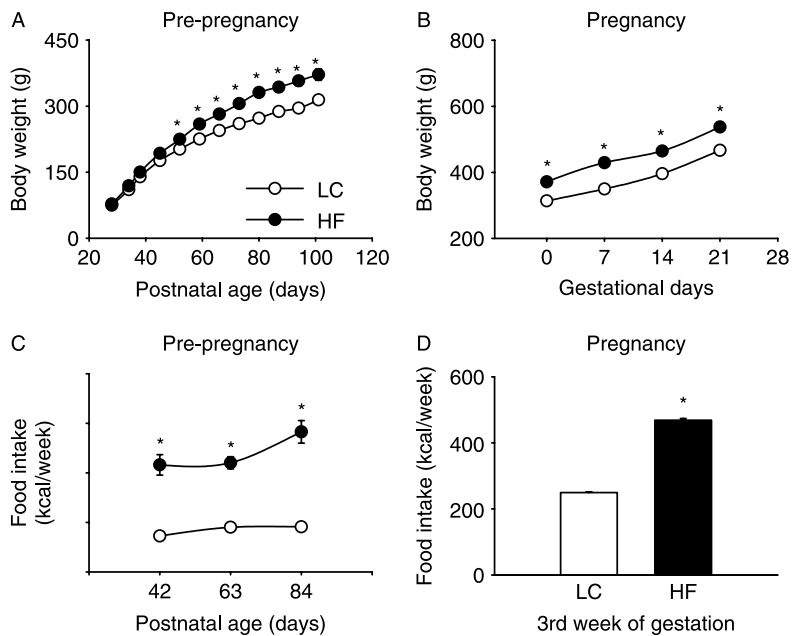

Figure 1 Body weights and food intake for HF and age-matched LC female rats in the pre-pregnancy and pregnancy periods. Body weights in the pre-pregnancy period from postnatal days 24 to 105 (A) and during pregnancy (B) and food intake in the pre-pregnancy period $(C)$ and during pregnancy (D) for HF and age-matched LC female rats. The results are expressed as means \pm S.E.M. $(n=6-8)$. $* P \leq 0.05$ compared with LC.

Insulin, leptin and glucose levels in the pre-pregnancy and pregnancy periods

Within 2 weeks of consumption of the high-fat diet, plasma leptin levels were significantly higher (1.98-fold increase; $P \leq 0 \cdot 05)$ in $\mathrm{HF}$ female rats (Fig. 2A). While plasma leptin levels continued to increase in both groups in the postweaning period, HF females had significantly higher plasma leptin levels compared with LC females at all the time points in the pre-pregnancy period (1.90-fold; $P \leq 0.05,1.99$-fold; $P \leq 0 \cdot 05$, and $2 \cdot 61$-fold $P \leq 0 \cdot 05$ on postnatal days 60,73 , and 87 respectively; Fig. 2A). On gestational day 21 there was a further heightened disparity $(2 \cdot 75$-fold increase; $P \leq 0 \cdot 05)$ in plasma leptin levels between the two groups of rats (Fig. 2A). Although, plasma insulin levels of HF and LC females were not different up to postnatal day 73 , they became significantly higher $(1 \cdot 48$-fold; $P \leq 0 \cdot 05)$ in HF females by postnatal day 87 and continued to be increased to $2 \cdot 34$-fold $(P \leq 0 \cdot 05)$ during late gestation (Fig. 2B). Both groups had similar glucose levels suggesting a state of insulin resistance $(78 \pm 8 \mathrm{mg} / \mathrm{dl}$ for LC and $74 \pm 10 \mathrm{mg} / \mathrm{dl}$ for HF in the pre-pregnancy period on postnatal day $87 ; 83 \pm 13 \mathrm{mg} / \mathrm{dl}$ for LC and $78 \pm 12 \mathrm{mg} / \mathrm{dl}$ for HF during pregnancy on gestational day 21).

\section{Characterization of fetal weights, leptin and insulin levels}

There is evidence that maternal leptin can cross the placenta and is a significant source of fetal leptin (Smith \& Waddell 2003) but there is little transplacental transfer of insulin (Boskovic et al. 2003). In our previous study, we showed that HF fetuses were hyperinsulinemic due to enhanced pancreatic insulin secretion (Srinivasan et al. 2006). Since, serum levels of leptin and insulin
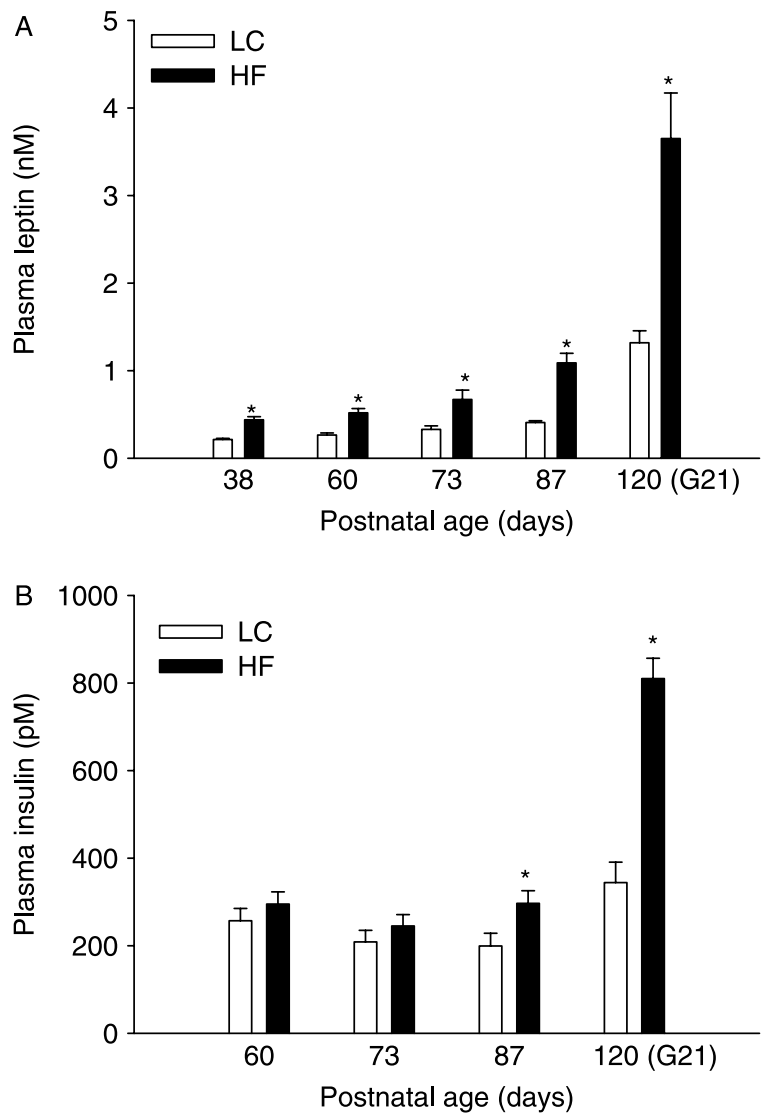

Figure 2 Plasma levels of leptin (A) and insulin (B) in HF and agematched LC female rats in the post-weaning period (during the prepregnancy and pregnancy periods). The results are expressed as means \pm S.E.M. $(n=6-12) .{ }^{*} P \leq 0 \cdot 05$ compared with LC. G21: gestational day 21 .

may affect fetal development, we evaluated their levels in the fetuses of LC mothers (FLC) and fetuses of HF mothers (FHF) The average term fetal weights $(5 \cdot 00 \pm 0.3 \mathrm{~g}$ for FLC and $5 \cdot 20 \pm 0 \cdot 2$ for FHF) and the average term placental weights $(\mathrm{FLC}=0.50 \pm 0.02 \mathrm{~g}$ and $\mathrm{FHF}=0.47 \pm 0.02 \mathrm{~g}$ ) were similar for both the groups. The average number of term fetuses in HF group was similar to that of the LC group (average litter size for $\mathrm{LC}=15 \cdot 1 \pm 1 \cdot 8$ vs $14 \cdot 1 \pm 2 \cdot 2$ for HF females). Fetal weight/ placental weight ratio was not significantly different between the two groups of fetuses (data not shown). Serum insulin levels of FHF were 1.62 -fold higher $(P \leq 0 \cdot 05)$ than that of FLC (Fig. 3A). The serum leptin levels of FHF were also significantly higher $(P \leq 0 \cdot 05)$ than that of FLC (Fig. 3B). In an earlier study we showed that fetal glucose levels were not different between the two groups of fetuses (Srinivasan et al. 2006).

Effect of HF diet on levels of appetite-regulating neuropeptides and components of leptin and insulin signaling

Quantitative RT-PCR Although it has been shown that leptin and insulin signaling pathways in the hypothalamus play 

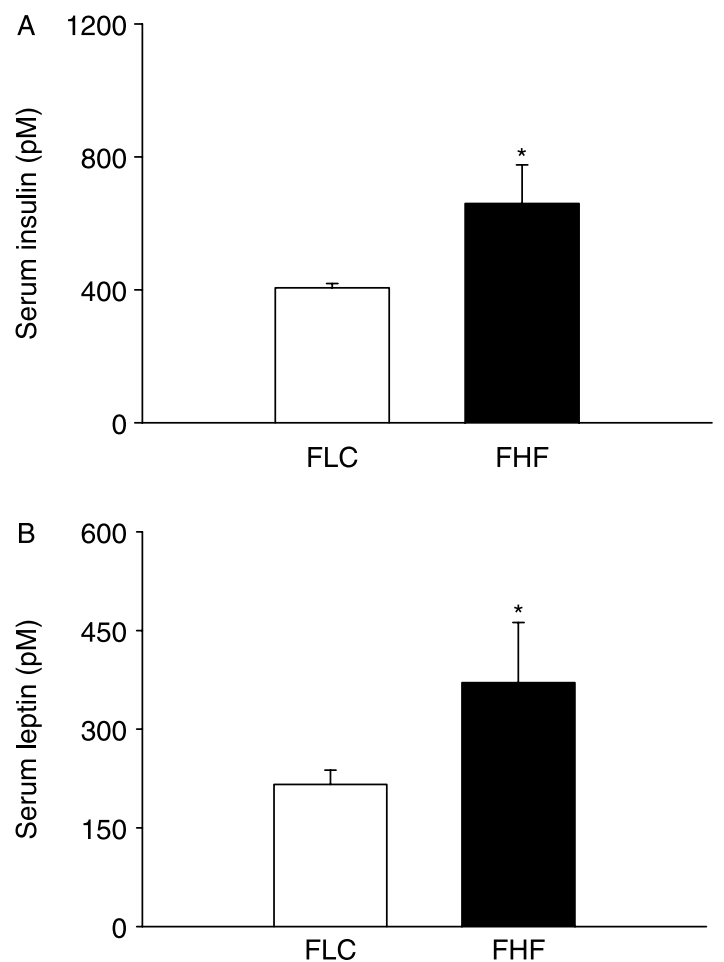

Figure 3 Serum levels of insulin (A) and leptin (B) in term fetuses of $\mathrm{LC}$ and $\mathrm{HF}$ female rats. The results are expressed as means \pm s.E.M. $(n=6-8) .{ }^{*} P \leq 0 \cdot 05$ compared with LC.

a pivotal role in the regulation of food intake in adults, it is not known if alterations in these signaling pathways are initiated during fetal development due to an adverse maternal intrauterine environment. In order to decipher the role of the obese/hyperinsulinemic maternal environment of the HF female rat on the development of programming effects at the level of insulin and leptin signaling in fetal hypothalami, the mRNA levels of the receptors and some of the proximal components were determined by real-time PCR. We observed a $3 \cdot 6$-fold $(P \leq 0 \cdot 05)$ increase in mRNA levels of OB-Rb in FHF hypothalami compared with FLC hypothalami (Fig. 4). This was accompanied by a $1 \cdot 72$-fold $(P \leq 0 \cdot 05)$ increase in levels of STAT-3 mRNA in FHF hypothalami (Fig. 4), the primary mediator of leptin's activity on the downstream neurons that express AgRP and NPY. There was no significant change in level of SOCS-3 mRNA. There was a $2 \cdot 24$-fold $(P \leq 0.05)$ increase in levels of the IR- $\beta$ in FHF hypothalami (Fig. 4). mRNA levels of AgRP and NPY were increased by $1 \cdot 77$-fold $(P \leq 0 \cdot 05)$ and $3 \cdot 41$-fold $(P \leq 0 \cdot 05$ respectively (Fig. 4) and POMC and melanocortin receptor 4 (MC4R) levels were elevated by $4 \cdot 29$-fold $(P \leq 0 \cdot 05)$ and 3.14-fold $(P \leq 0 \cdot 05)$ respectively in the FHF hypothalami compared with FLC hypothalami (Fig. 4).

Western blot analysis An increased OB-Rb mRNA level was associated with an increased level of OBRb protein by 2.08-fold in the FHF hypothalami (Fig. 5). However, total

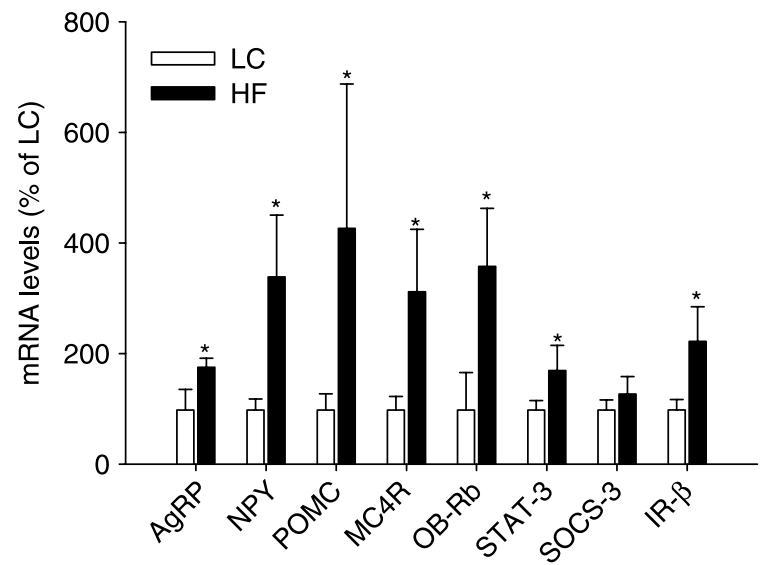

Figure $4 \mathrm{mRNA}$ levels of AgRP, NPY, POMC, MC4R, OB-Rb, STAT3 , SOCS-3 and IR- $\beta$ in the hypothalami of term fetuses of high-fatdiet fed (FHF) and laboratory chow fed (FLC) female rats. mRNA levels are normalized relative to $18 \mathrm{~S}$ as endogenous reference standard using the $\Delta \Delta C_{\mathrm{t}}$ comparative method. Results are expressed as means \pm S.E.M. $(n=5-7)$. ${ }^{*} P \leq 0 \cdot 05$ compared with LC.

STAT-3 protein level in the FHF hypothalami was only $85 \%$ of the FLC hypothalami $(P \leq 0 \cdot 05$; Fig. 5). No significant difference was observed in levels of SOCS-3 protein between the two groups.

Protein levels of IR- $\beta$ were also increased (Fig. 5) corresponding to the increased mRNA levels of IR- $\beta$ in FHF compared with FLC. However, IRS-2 protein amount in the FHF group was only $65 \%$ of the FLC group $(P \leq 0 \cdot 05$; Fig. 5$)$.

\section{Discussion}

The present study confirms our previous report about the consequences of maternal high-fat diet consumption leading to fetal programming (Srinivasan et al. 2006). It is possible that
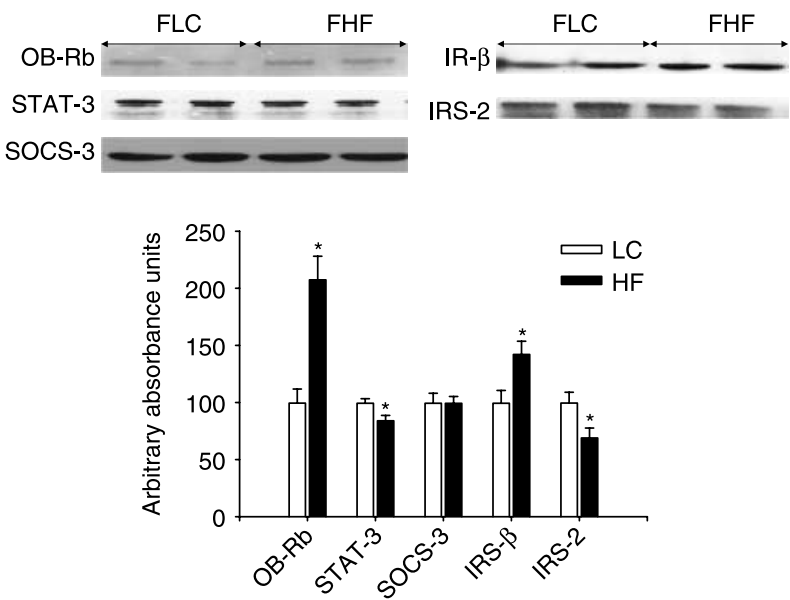

Figure 5 Western blot analysis of leptin (OB-Rb, STAT-3, SOCS-3) and insulin (IR- $\beta$, IRS-2) signal transduction components in the hypothalami of term FHF and FLC female rats. Results are expressed as means \pm s.E.M. $(n=5-7) .{ }^{*} P \leq 0.05$ compared with LC. 
the observed alterations in the maternal intrauterine environment and the resultant fetal programming effects could also be due to the reduced availability of carbohydratederived calories in the HF diet (due to increases in the fatderived calories). It extends the findings from fetal pancreatic insulin hypersecretion in the previous study to altered signaling in the hypothalamus of term fetuses of female rats fed a high-fat diet. This demonstrates that altered hormonal and metabolic milieu in obese mothers may play a significant role in establishing altered metabolic programming in the fetal period compounding postnatal effects. The study shows that HF fetuses are hyperleptinemic and hyperinsulinemic and points to the presence of abnormalities in the signal transduction pathways of leptin and insulin in the hypothalami of FHF-diet fed female rats. This is associated with increased levels of NPY and AgRP mRNAs in the hypothalamus which are key appetite-regulating neuropeptides in the postnatal period.

Our findings of hyperinsulinemia in the previous and current studies in fetuses exposed to a hyperinsulinemic/obese intrauterine environment in the HF female rats are closely related to findings of other investigators in various models of overnutrition during early periods of life. It has been shown that offspring of women with gestational diabetes have high insulin levels perinatally which continue into adult life (Kohlhoff \& Dorner 1990, Dorner \& Plagemann 1994). Similarly, rats reared in smaller litters also display hyperinsulinemia in early postnatal life (Kohlhoff \& Dorner 1990, Dorner \& Plagemann 1994, Plagemann et al. 1999b). Our earlier studies showed that HF fetal islets displayed a hypersecretory capacity which probably contributed to the observed fetal hyperinsulinemia (Srinivasan et al. 2006). It has been reported that NPY and AgRP neurons stimulate pancreatic insulin secretion (Szabo \& Szabo 1983). A plausible reason for the observed fetal hyperinsulinemia in term HF fetuses could be the observed increases in the mRNA levels of these neuropeptides in term fetal HF hypothalami. Rats reared in small litters and the offspring of diabetic women have been observed to be hyperleptinemic while those raised in large litters or exposed to maternal undernutrition have hypoleptinemia (Davidowa \& Plagemann 2000). Since rat fetuses do not possess much s.c. fat at birth (Kawai et al. 1997, Amico et al. 1998), increased adipogenesis is not likely to be the mechanism of hyperleptinemia. However, it has been shown that maternal leptin can be transported across the placenta and is a significant source of fetal leptin (Smith \& Waddell 2003). Therefore, we postulate that enhanced transplacental transport of leptin from mother to fetus may have contributed to the fetal hyperleptinemia observed in our study.

Leptin and insulin have important actions in the appetiteregulating neurons in the hypothalamus (Niswender \& Schwartz 2003). Binding of leptin and insulin to OBRb and IR- $\beta$ respectively stimulates downstream activity in their respective signaling pathways. This involves activation of nonreceptor Janus kinases followed by autophosphorylation of the receptor and binding of STATs. Specifically, STAT-3 isoform dimerizes and translocates to the nucleus to bind to the promoter region of the genes that regulate transcription (Fruhbeck 2006). It stimulates expression of POMC and MC4R genes (Bates \& Myers 2004) while suppressing expression of AgRP/NPY (Kitamura et al. 2006). Similarly, activation of tyrosine kinase activity of IR- $\beta$ leads to phosphorylation of IRS-2 followed by PI3K activation. This results in stimulation or repression of POMC and AgRP/NPY respectively (Plum et al. 2006). Also, SOCS-3 is involved in feedback inhibition of leptin receptor in response to leptin (Bjorbak et al. 2000) as well as targeting insulin receptor and IRS-2 for degradation (Ueki et al. 2004).

It has been previously reported that adult rats fed a hyperlipidemic diet display hyperleptinemia and hyperinsulinemia with resistance to their actions at the level of the hypothalamus. Specifically, there is reduced tyrosine phosphorylation of insulin receptor and IRS-2 with no change in their protein levels in the hypothalamus of adult high-fat-diet fed rats (De Souza et al. 2005). Also, there have been reports of decreased STAT-3 signaling in response to leptin in mice fed a high-fat diet pointing to abnormal transport as well as signal transduction (El-Haschimi et al. 2000). In our study, high levels of leptin and insulin in the HF fetuses in response to intrauterine environment were associated with enhanced mRNA and protein levels of their respective membrane receptors in the hypothalamus of HF fetuses. However, there was a significant decrease in the level of STAT-3 protein although its mRNA level was increased in the FHF hypothalamus. Transcriptional regulation has been considered the major point of regulation of protein production in eukaryotic cells but recent evidence brings the role of posttranscriptional processes to light. In this context, regulation of mRNA stability at cellular level is postulated to be a major control point of cellular mRNA levels (Staton et al. 2000). Hormones are postulated to play a major role in this process (Staton et al. 2000). Therefore, we suggest that altered hormonal milieu in the hypothalamus of HF fetuses may be the potential reason for observed discrepancy between mRNA and protein levels of STAT-3. Also, the protein level of IRS-2 in FHF hypothalamus was significantly decreased. This indicates impaired post-receptor signaling at the level of STAT-3 and IRS-2. SOCS-3 is a major endogenous feedback inhibitor of STAT-3 (Bjorbak et al. 2000) and IRS-2 (Ueki et al. 2004) but we did not find an increase in SOCS-3 mRNA or protein levels in our study.

The findings of increased NPY/AgRP in the HF rat fetus are in parallel with observations of other investigators in adult offspring exposed to maternal overnutrition (Muhlhausler et al. 2006). However, POMC and MC4R levels were increased. This is consistent with observations from another study where acute and chronic leptin treatment increased or had no effect on POMC level respectively (Proulx et al. 2002). Leptin and insulin normally act via STAT-3 and IRS-2 respectively to inhibit AgRP/NPY neurons while stimulating POMC neurons (Porte et al. 2002, Morton et al. 2005, Xu 
et al. 2005). Our findings of increased mRNA levels of AgRP and NPY with decreased levels of STAT-3 and IRS-2 proteins are suggestive of impairment of leptin and insulin signaling. In adult rats exposed to maternal overnutrition or overfed postnatally, resistance to actions of insulin and leptin results in abnormal appetite regulation, overweight and glucose intolerance.

Although leptin and insulin do not affect appetite in the fetal period, hyperleptinemia and hyperinsulinemia with decreased levels of STAT-3 and IRS-2 may have different implications for the developing fetus. Leptin has been shown to promote growth of arcuate neurons secreting NPY and AgRP preferentially in the neonatal period (Bouret et al. 2004, Horvath \& Bruning 2006). Also, it has been shown that perinatal hyperinsulinism in subcutaneously insulin-treated neonatal rats and offspring of gestational diabetic rats show hypoplasia and hypotrophy of the ventromedial nucleus, which is an important hypothalamic nucleus involved in inhibition of appetite and pancreatic insulin secretion (Dorner \& Plagemann 1994, Plagemann et al. 1999a). Thus, it has been suggested that perinatal hyperinsulinism and hyperleptinism may be neuroendocrine teratogenic risk factors. However, substrates involved in mediating these effects are still unknown. It has been recently shown that brain IRS-2 null mice exhibited abnormal neuron development and brain growth (Schubert et al. 2003) and it is predominantly distributed in brain areas regulating energy homeostasis (Pardini et al. 2006). Also, STAT-3 is known to maintain neural precursor cells in the mouse embryonic neocortex (Yoshimatsu et al. 2006). Therefore, it is likely that abnormal signaling of leptin and insulin via STAT-3 and IRS-2 respectively in term rat fetuses may lead to abnormal development of neurons and their projections leading to altered levels of appetite-regulating neuropeptides thus predisposing them to abnormal appetite regulation in the postnatal period. The possibility that altered post-transcriptional processes may be operational in decreased STAT-3 production will need to be explored since SOCS-3 is traditionally considered to be involved in impaired signaling was not increased here.

In summary, this study shows that abnormalities of leptin and insulin signaling are present in the critical period of fetal development at the levels of STAT-3 and IRS-2. This is associated with altered regulation of levels of appetiteregulating neuropeptides and may have a role in abnormal development of hypothalamic energy regulating neurons since these proteins are involved in neuronal development. This may provide an explanation to the observed phenotype of obesity and metabolic syndrome in the adult offspring of obese females. Therefore, this study points to a potential intrauterine programming effect of maternal high-fat diet with implications for abnormal appetite regulation in offspring in the postnatal period.

\section{Declaration of interest}

The authors declare that there is no conflict of interest that could be perceived as prejudicing the impartiality of the research reported.

\section{Funding}

This work was supported by National Institute of Health grant (DK-061518).

\section{References}

Amico JA, Thomas A, Crowley RS \& Burmeister LA 1998 Concentrations of leptin in the serum of pregnant, lactating, and cycling rats and of leptin messenger ribonucleic acid in rat placental tissue. Life Sciences 63 1387-1395.

Van Assche FA, Holemans K \& Aerts L 2001 Long-term consequences for offspring of diabetes during pregnancy. British Medical Bulletin 60 173-182.

Bates SH \& Myers MG 2004 The role of leptin $\rightarrow$ STAT3 signaling in neuroendocrine function: an integrative perspective. Journal of Molecular Medicine 82 12-20.

Bjorbak C, Lavery HJ, Bates SH, Olson RK, Davis SM, Flier JS \& Myers MG Jr 2000 SOCS3 mediates feedback inhibition of the leptin receptor via Tyr985. Journal of Biological Chemistry 275 40649-40657.

Boney CM, Verma A, Tucker R \& Vohr BR 2005 Metabolic syndrome in childhood: association with birth weight, maternal obesity, and gestational diabetes mellitus. Pediatrics 115 e290-e296.

Boskovic R, Feig DS, Derewlany L, Knie B, Portnoi G \& Koren G 2003 Transfer of insulin lispro across the human placenta: in vitro perfusion studies. Diabetes Care 26 1390-1394.

Bouret SG, Draper SJ \& Simerly RB 2004 Trophic action of leptin on hypothalamic neurons that regulate feeding. Science $304108-110$.

Davidowa H \& Plagemann A 2000 Decreased inhibition by leptin of hypothalamic arcuate neurons in neonatally overfed young rats. Neuroreport $112795-2798$

Dorner G \& Plagemann A 1994 Perinatal hyperinsulinism as possible predisposing factor for diabetes mellitus, obesity and enhanced cardiovascular risk in later life. Hormone and Metabolic Research 26 213-221.

El-Haschimi K, Pierroz DD, Hileman SM, Bjorbaek C \& Flier JS 2000 Two defects contribute to hypothalamic leptin resistance in mice with dietinduced obesity. Journal of Clinical Investigation 105 1827-1832.

Flegal KM, Carroll MD, Ogden CL \& Johnson CL 2002 Prevalence and trends in obesity among US adults, 1999-2000. Journal of the American Medical Association 288 1723-1727.

Fruhbeck G 2006 Intracellular signalling pathways activated by leptin. Biochemical Journal 393 7-20.

Horvath TL \& Bruning JC 2006 Developmental programming of the hypothalamus: a matter of fat. Nature Medicine 12 52-53 (discussion 53).

Kawai M, Yamaguchi M, Murakami T, Shima K, Murata Y \& Kishi K 1997 The placenta is not the main source of leptin production in pregnant rat: gestational profile of leptin in plasma and adipose tissues. Biochemical and Biophysical Research Communications 240 798-802.

Khan IY, Dekou V, Douglas G, Jensen R, Hanson MA, Poston L \& Taylor PD 2005 A high-fat diet during rat pregnancy or suckling induces cardiovascular dysfunction in adult offspring. American Journal of Physiology. Regulatory, Integrative and Comparative Physiology 288 R127-R133.

Kitamura T, Feng Y, Kitamura YI, Chua SC Jr, Xu AW, Barsh GS, Rossetti L \& Accili D 2006 Forkhead protein FoxO1 mediates Agrp-dependent effects of leptin on food intake. Nature Medicine 12 534-540.

Kohlhoff R \& Dorner G 1990 Perinatal hyperinsulinism and perinatal obesity as risk factors for hyperinsulinaemia in later life. Experimental and Clinical Endocrinology 96 105-108.

Kozak R, Richy S \& Beck B 2005 Persistent alterations in neuropeptide Y release in the paraventricular nucleus of rats subjected to dietary manipulation during early life. European Journal of Neuroscience 21 2887-2892.

Morton GJ, Gelling RW, Niswender KD, Morrison CD, Rhodes CJ \& Schwartz MW 2005 Leptin regulates insulin sensitivity via phosphatidylinositol-3-OH kinase signaling in mediobasal hypothalamic neurons. Cell Metabolism 2 411-420. 
Muhlhausler BS, Adam CL, Findlay PA, Duffield JA \& McMillen IC 2006 Increased maternal nutrition alters development of the appetite-regulating network in the brain. FASEB Journal 20 1257-1259.

Niswender KD \& Schwartz MW 2003 Insulin and leptin revisited: adiposity signals with overlapping physiological and intracellular signaling capabilities. Frontiers in Neuroendocrinology $241-10$.

Pardini AW, Nguyen HT, Figlewicz DP, Baskin DG, Williams DL, Kim F \& Schwartz MW 2006 Distribution of insulin receptor substrate-2 in brain areas involved in energy homeostasis. Brain Research 1112 169-178.

Parsons TJ, Power C \& Manor O 2001 Fetal and early life growth and body mass index from birth to early adulthood in 1958 British cohort: longitudinal study. BMJ 323 1331-1335.

Pettitt DJ 1996 Diabetes in subsequent generations. In Diabetes and Pregnancy. An International Aproach to Diagonosis and Management, pp 367-376. Eds A Dornhorst \& DR Hadden. Chichester: John Wiley and Sons.

Plagemann A 2005 Perinatal programming and functional teratogenesis: impact on body weight regulation and obesity. Physiology and Behavior $\mathbf{8 6}$ 661-668.

Plagemann A, Harder T, Janert U, Rake A, Rittel F, Rohde W \& Dorner G 1999 a Malformations of hypothalamic nuclei in hyperinsulinemic offspring of rats with gestational diabetes. Developmental Neuroscience 21 58-67.

Plagemann A, Harder T, Rake A, Voits M, Fink H, Rohde W \& Dorner G $1999 b$ Perinatal elevation of hypothalamic insulin, acquired malformation of hypothalamic galaninergic neurons, and syndrome X-like alterations in adulthood of neonatally overfed rats. Brain Research 836 146-155.

Plum L, Belgardt BF \& Bruning JC 2006 Central insulin action in energy and glucose homeostasis. Journal of Clinical Investigation 116 1761-1766.

Porte D Jr, Baskin DG \& Schwartz MW 2002 Leptin and insulin action in the central nervous system. Nutrition Reviews 60 S20-S29 (discussion S68-84, 85-27).

Proulx K, Richard D \& Walker CD 2002 Leptin regulates appetite-related neuropeptides in the hypothalamus of developing rats without affecting food intake. Endocrinology 143 4683-4692.

Schubert M, Brazil DP, Burks DJ, Kushner JA, Ye J, Flint CL, Farhang-Fallah J, Dikkes P, Warot XM, Rio C et al. 2003 Insulin receptor substrate-2 deficiency impairs brain growth and promotes tau phosphorylation. Journal of Neuroscience 23 7084-7092.

Schwartz MW, Woods SC, Porte D, Seeley RJ \& Baskin DG 2000 Central nervous system control and food intake. Nature 404 661-671.

Smith JT \& Waddell BJ 2003 Leptin distribution and metabolism in the pregnant rat: transplacental leptin passage increases in late gestation but is reduced by excess glucocorticoids. Endocrinology 144 3024-3030.

De Souza CT, Araujo EP, Bordin S, Ashimine R, Zollner RL, Boschero AC, Saad MJ \& Velloso LA 2005 Consumption of a fat-rich diet activates a proinflammatory response and induces insulin resistance in the hypothalamus. Endocrinology 146 4192-4199.
Srinivasan M, Katewa SD, Palaniyappan A, Pandya JD \& Patel MS 2006 Maternal high-fat diet consumption results in fetal malprogramming predisposing to the onset of metabolic syndrome-like phenotype in adulthood. American Journal of Physiology. Endocrinology and Metabolism 291 E792-E799.

Srinivasan M, Mitrani P, Sadhanandan G, Dodds C, Shbeir-ElDika S, Thamotharan S, Ghanim H, Dandona P, Devaskar SU \& Patel MS 2008 A high-carbohydrate diet in the immediate postnatal life of rats induces adaptations predisposing to adult-onset obesity. Journal of Endocrinology 197 $565-574$.

Staton JM, Thomson AM \& Leedman PJ 2000 Hormonal regulation of mRNA stability and RNA-protein interactions in the pituitary. Journal of Molecular Endocrinology 25 17-34.

Szabo AJ \& Szabo O 1983 Insulin injected into CNS structures or into the carotid artery: effect on carbohydrate homeostasis of the intact animal. Advances in Metabolic Disorders 10 385-400.

Taylor PD \& Poston L 2007 Developmental programming of obesity in mammals. Experimental Physiology 92 287-298.

Ueki K, Kondo T \& Kahn CR 2004 Suppressor of cytokine signaling 1 (SOCS-1) and SOCS-3 cause insulin resistance through inhibition of tyrosine phosphorylation of insulin receptor substrate proteins by discrete mechanisms. Molecular and Cellular Biology 24 5434-5446.

Valassi E, Scacchi M \& Cavagnini F 2008 Neuroendocrine control of food intake. Nutrition, Metabolism, and Cardiovascular Diseases 18 158-168.

Villamor E \& Cnattingius S 2006 Interpregnancy weight change and risk of adverse pregnancy outcomes: a population-based study. Lancet $\mathbf{3 6 8}$ 1164-1170.

Whitaker RC 2004 Predicting preschooler obesity at birth: the role of maternal obesity in early pregnancy. Pediatrics 114 e29-e36.

Xu AW, Kaelin CB, Takeda K, Akira S, Schwartz MW \& Barsh GS 2005 PI3K integrates the action of insulin and leptin on hypothalamic neurons. Journal of Clinical Investigation 115 951-958.

Yogev Y \& Langer O 2008 Pregnancy outcome in obese and morbidly obese gestational diabetic women. European Journal of Obstetrics, Gynecology, and Reproductive Biology 137 21-26.

Yoshimatsu T, Kawaguchi D, Oishi K, Takeda K, Akira S, Masuyama N \& Gotoh Y 2006 Non-cell-autonomous action of STAT3 in maintenance of neural precursor cells in the mouse neocortex. Development $\mathbf{1 3 3}$ $2553-2563$.

\section{Received in final form 5 December 2008 \\ Accepted 9 December 2008 \\ Made available online as an Accepted Preprint 11 December 2008}

